Research Article

\title{
Research on Ignition Energy Characteristics and Explosion Propagation Law of Coal Dust Cloud under Different Conditions
}

\author{
Tianqi Liu $\left(\mathbb{D}\right.$, Ruiheng Jia $\mathbb{D}^{D}$, Ruicheng Sun $\mathbb{D}^{D}$, Weiye Tian $\mathbb{D}^{D}$, Ning Wang $\mathbb{D}^{D}$, \\ and Zhixin Cai ii
}

School of Safety Engineering, Shenyang Aerospace University, Shenyang, Liaoning 110136, China

Correspondence should be addressed to Tianqi Liu; liutianqi613@163.com

Received 3 July 2021; Accepted 28 August 2021; Published 6 September 2021

Academic Editor: Zhengbiao Peng

Copyright (C) 2021 Tianqi Liu et al. This is an open access article distributed under the Creative Commons Attribution License, which permits unrestricted use, distribution, and reproduction in any medium, provided the original work is properly cited.

\begin{abstract}
To study the ignition energy characteristics and explosion propagation law of coal dust cloud, a kind of coal dust cloud is studied through experiment and numerical simulation under different conditions. The result indicated that ignition delay time and dust spray pressure have obvious effects on the minimum ignition energy of coal dust cloud. CFD theory is used to simulate the explosion flame propagation. It is found that the simulation error of flame propagation distance is acceptable and the simulation result is consistent with the experimental result. When the spray pressure is $0.06 \mathrm{MPa}$, the flame propagation distance is the farthest, indicating that the turbulence of coal dust cloud is the largest at this condition. As the ignition temperature increases, the flame propagation distance continues to increase, proving that ignition temperature has an obvious effect on the flame propagation process of coal dust cloud explosion.
\end{abstract}

\section{Introduction}

The ignition characteristics and explosion propagation characteristics of coal dust cloud are important parameters to characterize the explosion possibility and intensity of coal dust [1]. The propagation distance, the duration, and the spreading velocity of explosion flame in a confined space have huge impact on the intensity and destructiveness of coal dust explosion $[2,3]$. Due to the complexity and variability of the working environment and operating condition in the underground coal mine, the ignition characteristics and explosion propagation law of coal dust cloud are highly variable in the process of its generation and propagation under the effects of different kinds of factors $[4,5]$. Nowadays, with the rapid development of powder technology and CFD theory, the research results about flame characteristics are of great significance for mastering ignition characteristics and explosion propagation law $[6,7]$.

Coal dust explosion is the rapid combustion chemical reaction with turbulent flame shock wave. Previous studies have found that gas explosion characteristics are significantly variable due to the difference of explosive space structures [8-12]. Meanwhile, some research studies have focused on flame structure and propagation process during dust explosion [13-16]. Based on theoretic study of dust cloud ignition and using talc dust, lycopodium and maize starch powder as test samples, Eckhoff [17] researched on the effect of primary particle size distribution, degree of deagglomeration of the dust particles, dust concentration distribution in the cloud, and the cloud turbulence on the ignition sensitivity and explosion violence of dust clouds. Oran [18] studied the flame structure of dilute and dense layered coal-dust explosion which is caused by gas explosion. Kosinski [19] studied the probability of dust ignition and explosion in the interconnected vessels based on the Eulerian-Eulerian model, where the solid phase is modelled as a second fluid.

But the mechanism of coal dust explosion has not been thoroughly understood so far. Therefore, it is necessary to carry out further experimental and numerical research on ignition characteristics and explosion propagation law to reveal the mechanism of coal dust explosion in confined space. With the development of mechanics of explosion and computational fluid dynamics (CFD), numerical simulation 
method has become the significant tool for further research $[20,21]$. It is hopeful that the CFD numerical simulation technology may become a design tool for the suppression of explosion process, which indicates that the simulation results are of great significance to industrial safety prevention.

In this paper, a kind of coal dust cloud was applied to conduct the experiments under different conditions in confined space. Compared with the experiment, CFD theory was used for simulating flame propagation characteristics under different conditions by which the mechanism of coal dust explosion can be better understood.

\section{Experimental}

2.1. Experimental Apparatus. In experimental part, there are two experimental devices, namely, the minimum ignition energy test device for coal dust cloud and the test device for flame propagation characteristics of coal dust cloud explosion. The ignition and explosion of coal dust cloud are closely related. The easier the coal dust cloud is to be ignited, the smaller the corresponding minimum ignition energy, and the greater the risk of explosion. The minimum ignition energy test device for coal dust cloud is shown in Figure 1. The device is mainly composed of a coal dust injection diffusion system, an electric spark generation system, a tube body system, and an ignition energy data collection system. Among them, the coal dust injection diffusion system uses a diffuser to form a coal dust cloud. In order to avoid the overflow of flying coal dust and combustion gas-solid products, the experiment process is carried out in a fume hood.

The test device for flame propagation characteristics of coal dust cloud explosion is shown in Figure 2, which is composed of a glass pipeline system, a dust spray system, a high temperature ignition system, a camera system, a bracket system, a data collection system, and a pipeline cleaning system. The glass pipeline is 1.4 meters long. The outer wall of the pipeline is marked with the unit of length in centimeters. After putting two grams of coal dust into the coal sample tube, the microair compressor will form highpressure air, and the coal dust in the coal sample tube will be brought into the glass pipeline to form a suspended dust cloud, which will explode in the vicinity of the high-temperature platinum wire. The high temperature platinum wire is $0.2 \mathrm{~m}$ apart from the coal sample tube.

In the experiment, the experimental condition parameters should be set according to the relevant experimental requirements as follows: The initial dust spray pressure is set to $0.05 \mathrm{MPa}$, which can affect the turbulence intensity of coal

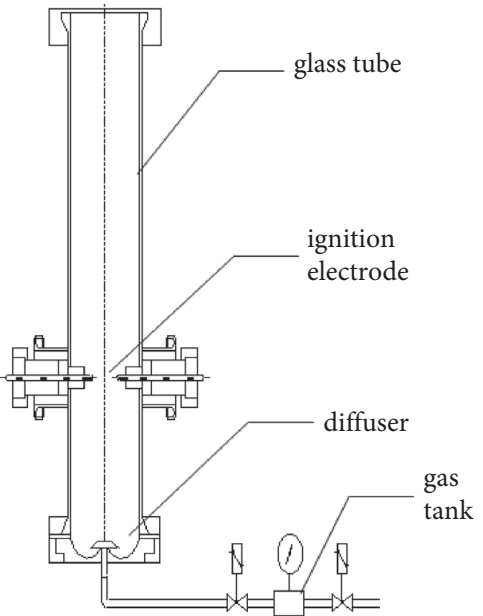

FIGURE 1: Experimental apparatus.

dust cloud and the initial velocity of the explosion flame. The ignition temperature of the high temperature platinum wire is set to $1373 \mathrm{~K}$, which can be set up to $1473 \mathrm{~K}$ by the limit of the working temperature of horizontal glass pipeline. Before the experiment, two grams of coal dust is put into the coal sample tube.

2.2. Experimental Materials. The coal dust sample is selected from Pinggou Coal Mine of China. The proximate and ultimate analyses of coal dust sample are summarized in Table 1. It is found that the selected lignite sample belongs to high volatile coal dust. The distribution of coal dust particle size is observed by the laser particle size analyzer, as shown in Figure 3. It can be seen that most of the coal dust particles have the particle size of less than $100 \mu \mathrm{m}$ with irregular shapes, and the median diameter is $75 \mu \mathrm{m}$, which satisfies the requirement of coal dust explosion.

\section{Numerical Simulation}

\subsection{Numerical Model of Coal Dust Explosion Dynamic Propagation}

3.1.1. Moisture Precipitation Model. After the coal dust particles move to the vicinity of the high temperature ignition region and are heated, the moisture will be removed from coal dust particles. The moisture precipitation process of coal dust particles can be described by the droplet evaporation model, in which the calculation formula of the moisture precipitation rate is as follows [22]:

$$
m_{w}= \begin{cases}-\pi \cdot d \cdot \mathrm{Nu} \cdot D_{s} \cdot \rho_{s} \cdot \ln \left(1+\frac{Y_{\mathrm{H}_{2} \mathrm{O}, s}-Y_{\mathrm{H}_{2} \mathrm{O}, g}}{1-Y_{\mathrm{H}_{2} \mathrm{O}, s}}\right), & T_{p}<T_{g}, \\ -\pi \cdot d \cdot \mathrm{Nu} \cdot \frac{\lambda_{s}}{C_{p s}} \cdot \ln \left[1+\frac{C_{p s}\left(T-T_{p}\right)}{1-L_{w}}\right], & T_{p}>T_{g},\end{cases}
$$




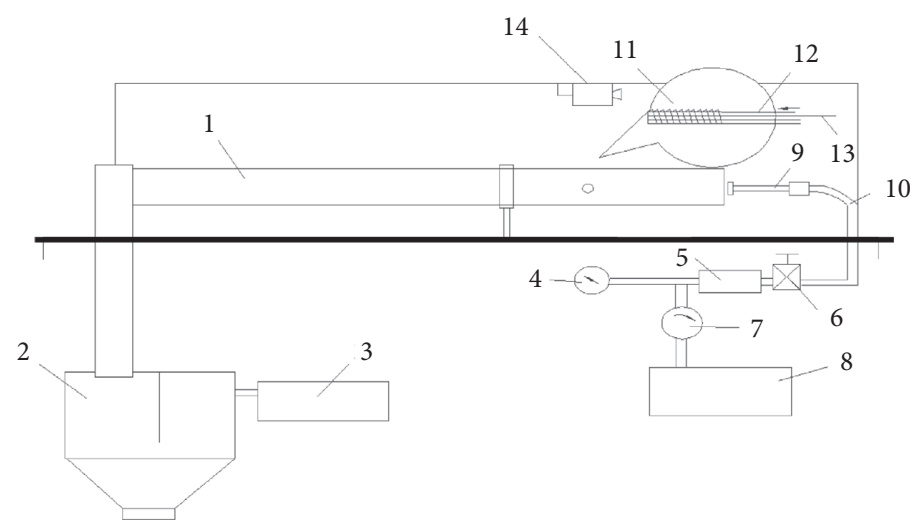

FiguRE 2: Structure of experimental apparatus. 1 glass pipeline; 2 dust collection region; 3 dust cleaner; 4 pressure gauge; 5 air chamber; 6 electromagnetic valve; 7 regulating valve; 8 micro air compressor; 9 coal sample tube; 10 bent pipe; 11 platinum wire; 12 heater; 13 thermocouple; 14 camera.

TABle 1: Proximate and ultimate analyses of coal dust sample.

\begin{tabular}{llccccc}
\hline & \multicolumn{2}{l}{ Proximate analysis (\%) } & \multicolumn{3}{c}{ Ultimate analysis (\%) } \\
\hline $\mathrm{M}_{\mathrm{ad}}$ & $\mathrm{A}_{\mathrm{ad}}$ & $\mathrm{V}_{\mathrm{ad}}$ & $\mathrm{FC}_{\mathrm{ad}}$ & $\mathrm{C}$ & $\mathrm{H}$ & $\mathrm{O}$ \\
4.17 & 7.25 & 39.80 & 48.78 & 61.28 & 3.13 & 32.55 \\
\hline
\end{tabular}

$\mathrm{M}_{\mathrm{ad}}$ : air-dried moisture content; $\mathrm{A}_{\mathrm{ad}}$ : air-dried ash; $\mathrm{V}_{\mathrm{ad}}$ : air-dried volatile; $\mathrm{FC}_{\mathrm{ad}}$ : air-dried fixed carbon.

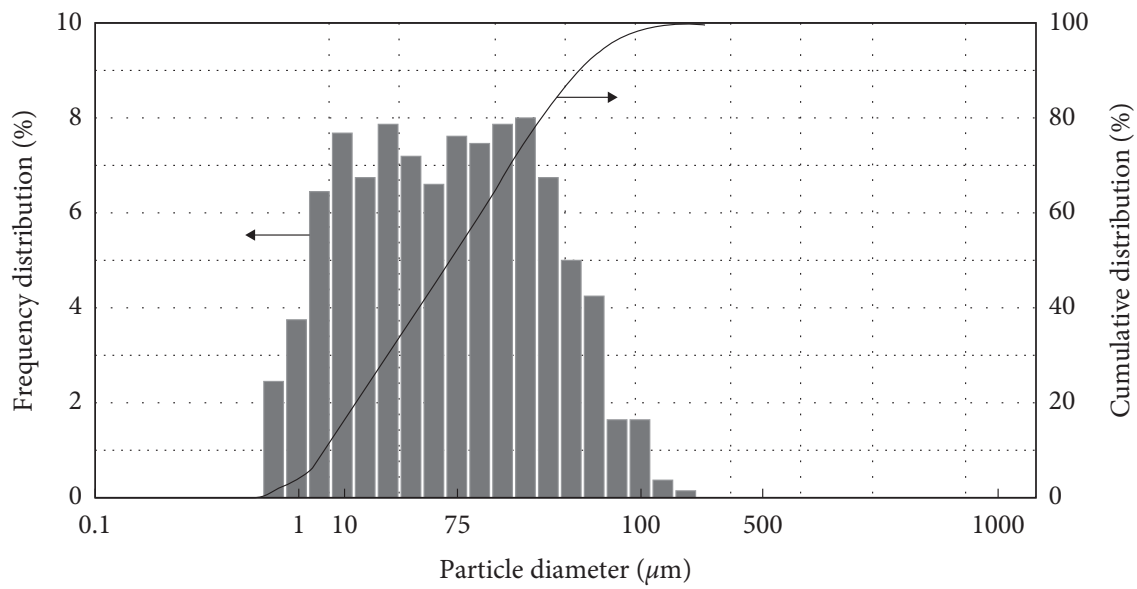

FIGURE 3: Diameter distribution of coal dust particles.

where $m_{w}$ is the moisture precipitation rate; $d$ is the particle diameter; $\mathrm{Nu}$ is the Nusselt number of particles; $D_{s}$ is the diffusion coefficient of component phase $s ; \rho_{s}$ is the apparent density of coal dust particle; $Y_{\mathrm{H}_{2} \mathrm{O}, \mathrm{s}}$ is the water vapor concentration on the surface of particles; $Y_{\mathrm{H}_{2} \mathrm{O}, g}$ is the water vapor concentration in the computational grid in which the particles are located; $T_{p}$ is the temperature of particles; $T_{g}$ is the temperature of gas phase; $\lambda_{s}$ is the coefficient of thermal conductivity; $C_{p s}$ is the specific heat at constant pressure; and $L_{w}$ is the specific heat capacity of water.

3.1.2. Turbulent Combustion Model of Dust Volatile Content. The turbulent combustion model of coal dust volatile content is a typical homogeneous combustion reaction model. Because of the extremely fast turbulent combustion reaction rate during the explosion process, the eddy dissipation model is used to describe the dust volatile content turbulent combustion process. The dust volatile content of coal dust is abbreviated as $V$, whose turbulent combustion reaction mechanism can be described as follows:

$$
\left\{\begin{array}{l}
\mathrm{V}+\mathrm{O}_{2} \longrightarrow \mathrm{CO}+\mathrm{CO}_{2}+\mathrm{H}_{2} \mathrm{O}+\mathrm{N}_{2} \\
\mathrm{CO}+0.5 \mathrm{O}_{2}=\mathrm{CO}_{2}
\end{array}\right.
$$

In the turbulent combustion reaction, the turbulent combustion rate depends not only on the chemical kinetic field but also on the flow field in the explosion space, which can be described as follows [23]:

$$
R_{\mathrm{fu}, T}=-\frac{A \cdot \rho \cdot g_{\mathrm{fu}}^{1 / 2} \cdot \varepsilon}{k},
$$


where $R_{\mathrm{fu}, T}$ is the rate of turbulent combustion; $A$ is the constant of combustion rate; $\rho$ is the density; $g_{\mathrm{fu}}$ is the ripple mean square of the fuel mass fraction; $\varepsilon$ is the dissipation rating of turbulent kinetic energy; and $k$ is the turbulent kinetic energy.

3.1.3. Turbulent Flow Model of Gas Phase. The coal dust explosion process contains complex turbulent flow of gas phase. The standard $k-\varepsilon$ model is commonly used in previous researches as the gas phase turbulent flow model due to its good robustness and convergence, which is shown in $[24,25]$.

3.2. Parameter Setting of Simulation. To ensure the reliability of the simulation results, the parameter settings of the initial conditions are completely in accordance with the experimental conditions. The initial pressure in the horizontal pipeline space is set to $0.1 \mathrm{MPa}$, and the flow field of the explosion space is set to be incompressible. This is determined by the conditions of the selected explosion numerical model. The initial temperature of the high temperature ignition region is set to $1373 \mathrm{~K}$.

Coal dust particles are set as highly volatile spheres. The density of coal dust particles is set to $1000 \mathrm{~kg}\left(\mathrm{~m}^{3}\right)$, the specific heat of coal dust is set to $1100 \mathrm{~J} /(\mathrm{kg} \cdot \mathrm{K})$, the volatile content of coal dust is set to $39.80 \%$, the dust volatile content release temperature is set to $773 \mathrm{~K}$, the thermal expansion coefficient of coal dust is set to 2 , and the coke burnout equivalent ratio of lignite is set to 2.67 .

\section{Results and Discussion}

4.1. Experimental Ignition Energy Characteristics of Coal Dust Cloud under Different Conditions. First, the test result of minimum ignition energy of coal dust cloud is shown in Table 2 . It can be seen that the test conditions mainly include ignition delay time and dust spray pressure. When the ignition delay time is $1 \mathrm{~s}$ and the dust spray pressure is $0.2 \mathrm{MPa}$, the test result of minimum ignition energy of coal dust cloud is $30 \mathrm{~mJ}$. The interval between the start of the dust injection and the spark discharge is called the ignition delay time of the coal dust cloud, the dust spray pressure can directly affect the turbulence intensity of coal dust cloud in the glass tube, and changes in these two parameters will affect the minimum ignition energy of coal dust cloud.

In order to study the variation law of minimum ignition energy of coal dust cloud with ignition delay time, further experiments are carried out while keeping other experimental parameters unchanged. Set the ignition delay time to $0.5 \mathrm{~s}, 0.7 \mathrm{~s}, 1 \mathrm{~s}, 1.3 \mathrm{~s}, 1.5 \mathrm{~s}$, and $1.8 \mathrm{~s}$, the experimental results of minimum ignition energy of coal dust cloud under different ignition delay time are shown in Figure 4. The change of the minimum ignition energy of the coal dust cloud shows a downward trend first and then rises. When the ignition delay time is $1 \mathrm{~s}$, the minimum ignition energy is the smallest, which indicates that the coal dust cloud has the strongest turbulence and reaches the most ignitable state. When the ignition delay time is greater than $1 \mathrm{~s}$, the minimum ignition energy becomes significantly larger,
Table 2: Minimum ignition energy of coal dust cloud.

\begin{tabular}{lccc}
\hline \multirow{2}{*}{ Type of coal dust } & \multicolumn{3}{c}{ Test conditions } \\
& $t_{0}(\mathrm{~s})$ & $P_{0}(\mathrm{MPa})$ & $E_{c}(\mathrm{~mJ})$ \\
\hline Lignite & 1 & 0.2 & 30
\end{tabular}

$t_{0}$ : ignition delay time; $P_{0}$ : dust spray pressure; $E_{c}$ : minimum ignition energy of coal dust cloud.

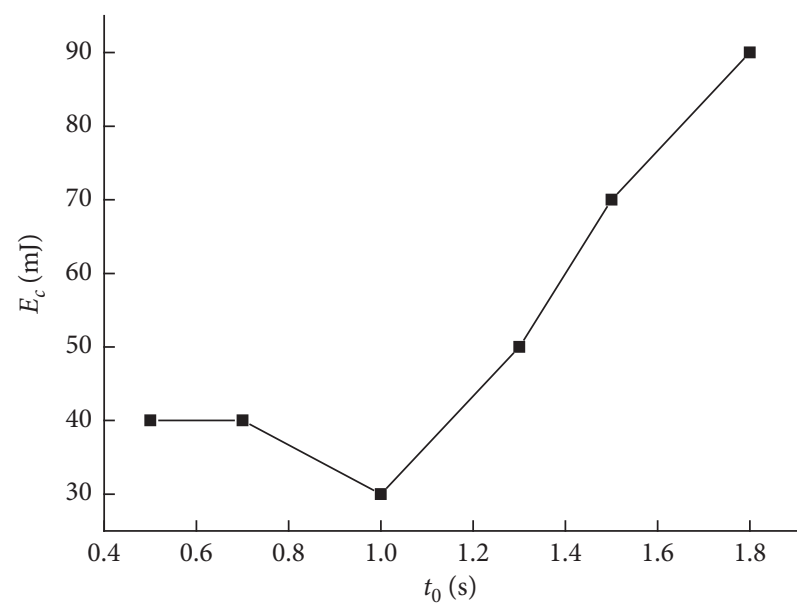

FIgURE 4: Change trend of minimum ignition energy of coal dust cloud with ignition delay time.

indicating that the gravity sedimentation effect has an extremely significant effect on the sinking of coal dust particles. When the ignition delay time is less than $1 \mathrm{~s}$, the coal dust particles are in a state of rapid diffusion under the action of the ejector pressure at the outlet of the diffuser and are not evenly dispersed in the ignition source.

In order to study the effect of dust spray pressure on minimum ignition energy of coal dust cloud, the dust spray pressure of the experiment is set to $0.2 \mathrm{MPa}, 0.3 \mathrm{MPa}$, 0.4 MPa, 0.5 $\mathrm{MPa}, 0.6 \mathrm{MPa}, 0.7 \mathrm{MPa}, 0.8 \mathrm{MPa}$, and 0.9 $\mathrm{MPa}$, respectively. The experimental results are shown in Figure 5. With the increase of dust spray pressure, the minimum ignition energy of coal dust cloud shows a trend of first decreasing and then increasing. When the dust spray pressure is $0.3-0.4 \mathrm{MPa}$, the coal dust cloud is the easiest to be ignited, and the corresponding explosion risk is greater. Due to the relatively high volatile content of coal dust sample, the rate of release of combustible gas is relatively fast in high temperature environments. Therefore, when the dust spray pressure is $0.3-0.4 \mathrm{MPa}$, in the case of low turbulence, the coal dust cloud can be ignited.

4.2. Comparison of Experimental and Numerical Flame Propagation Characteristics. The test device for flame propagation characteristics of coal dust cloud explosion is used to test flame propagation distance of coal dust cloud explosion. The experimental and numerical results of flame propagation distance are shown in Figure 6. It can be found that the simulation result is basically consistent with the experimental result, and the simulation error is within the acceptable range. At the time of $0.1 \mathrm{~s}, 0.2 \mathrm{~s}, 0.3 \mathrm{~s}, 0.4 \mathrm{~s}$, and 


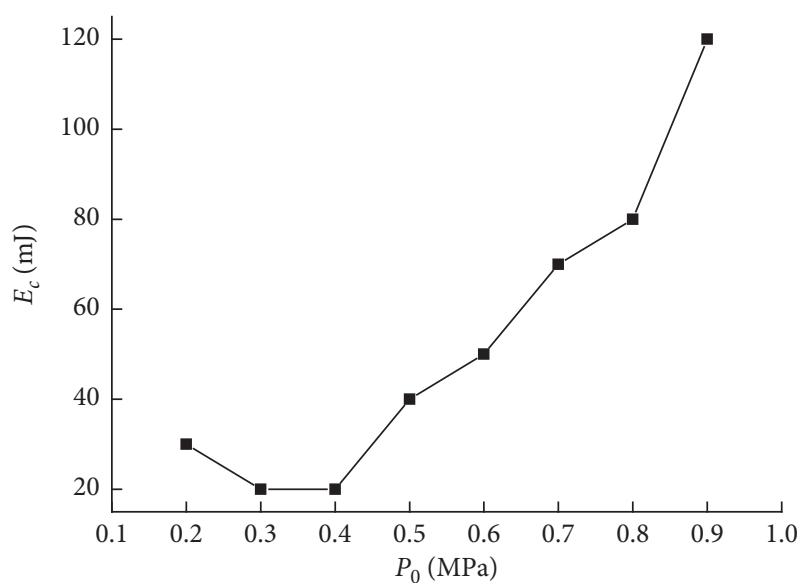

FIGURE 5: Change trend of minimum ignition energy of coal dust cloud with dust spray pressure.

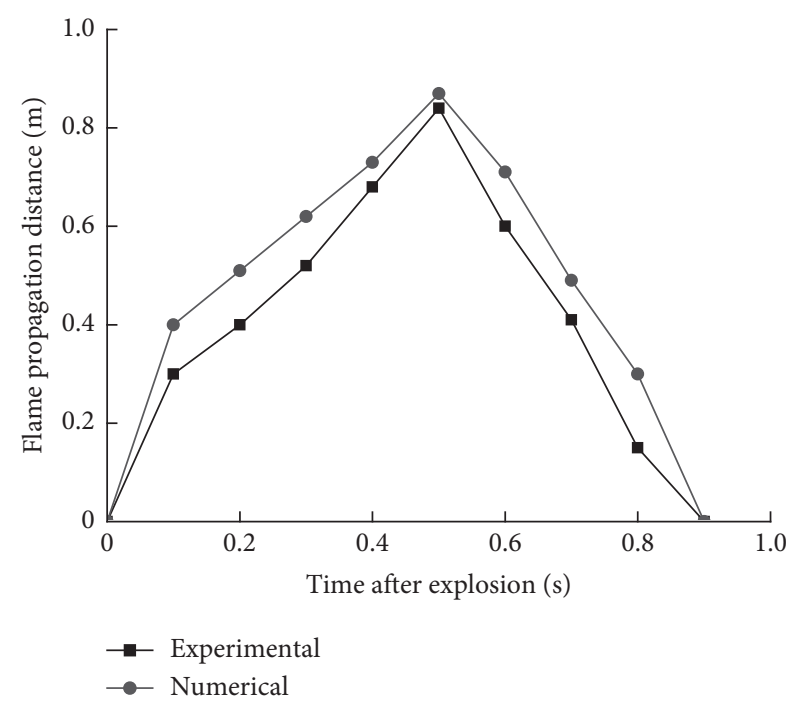

FIGURE 6: Experimental and numerical results of flame propagation distance.

$0.5 \mathrm{~s}$ after explosion, the flame propagation distance is $0.3 \mathrm{~m}$, $0.4 \mathrm{~m}, 0.52 \mathrm{~m}, 0.68 \mathrm{~m}$, and $0.84 \mathrm{~m}$. Simulation results are a little bit larger than experimental results. This is because the numerical models are simplified. At the time of $0.5 \mathrm{~s}$ after explosion, flame propagates to the farthest distance, the experimental flame propagation distance is $0.84 \mathrm{~m}$, and the numerical flame propagation distance is $0.87 \mathrm{~m}$, so the simulation error is $0.03 \mathrm{~m}$, which proves that the simulation accuracy is acceptable.

At the time of $0.5 \mathrm{~s}$ after explosion, the simulation result of flame propagation characteristics in pipeline space is shown in Figure 7 . It is found that the flame temperature reaches $1150 \mathrm{~K}$ at the cross section $Z=0.6 \mathrm{~m}$. At the cross section of $Z=0.8 \mathrm{~m}, Z=1 \mathrm{~m}, Z=1.2 \mathrm{~m}$, and $Z=1.4 \mathrm{~m}$, the closer to the center of the cross sections, the greater the numerical flame temperature, which is mainly affected by the explosion propagation dynamics. But in cross section $Z=0.2 \mathrm{~m}$ and $Z=0.4 \mathrm{~m}$, it shows that the closer to the center of cross sections, the lower the flame temperature. It is mainly because they are located behind the explosion source, and the temperature generated by the explosion propagates back along the pipe wall.

4.3. Experimental and Numerical Flame Propagation Law of Coal Dust Explosion under Different Conditions. The flame propagation process of coal dust explosion will be affected by many factors. In order to study the effect of dust spray pressure and ignition temperature on coal dust explosion flame, experimental tests and numerical simulations are carried out, respectively.

First, set the dust spray pressure to $0.03 \mathrm{MPa}, 0.04 \mathrm{MPa}$, $0.05 \mathrm{MPa}, 0.06 \mathrm{MPa}$, and $0.07 \mathrm{MPa}$, and the experimental results and simulation results of the flame propagation distance obtained are shown in Figure 8. It is obtained that when the dust spray pressure is set to $0.03 \mathrm{MPa}, 0.04 \mathrm{MPa}$, 0.05 $\mathrm{MPa}, 0.06 \mathrm{MPa}$, and $0.07 \mathrm{MPa}$, the experimental flame propagation distance is $0.22 \mathrm{~m}, 0.51 \mathrm{~m}, 0.84 \mathrm{~m}, 0.86 \mathrm{~m}$, and $0.75 \mathrm{~m}$, the numerical flame propagation distance is $0.28 \mathrm{~m}$, $0.55 \mathrm{~m}, 0.87 \mathrm{~m}, 0.93 \mathrm{~m}$, and $0.81 \mathrm{~m}$, the simulation result is a bit larger than the experimental result, but the maximum error of the simulation is $0.07 \mathrm{~m}$, so the accuracy of the simulation is acceptable. It can also be obtained that when the dust spray pressure is less than $0.05 \mathrm{MPa}$, the initial turbulence of the coal dust cloud is small, which is not conducive to the full spread and development of the flame. When the spray pressure is $0.06 \mathrm{MPa}$, the flame propagation distance is the farthest, indicating that the turbulence of the coal dust cloud is the largest at this time, and the explosion risk is also the largest.

In order to study the influence of ignition temperature on flame propagation distance of coal dust cloud explosion, the ignition temperature is set to $1373 \mathrm{~K}, 1383 \mathrm{~K}, 1393 \mathrm{~K}$, $1403 \mathrm{~K}, 1413 \mathrm{~K}, 1423 \mathrm{~K}, 1433 \mathrm{~K}, 1443 \mathrm{~K}, 1453 \mathrm{~K}, 1463 \mathrm{~K}$, and $1473 \mathrm{~K}$, respectively. The experimental and numerical flame propagation distance is shown in Figure 9. It can be obtained that when the ignition temperature is $1373 \mathrm{~K}, 1383 \mathrm{~K}$, $1393 \mathrm{~K}, 1403 \mathrm{~K}, 1413 \mathrm{~K}, 1423 \mathrm{~K}, 1433 \mathrm{~K}, 1443 \mathrm{~K}, 1453 \mathrm{~K}$, $1463 \mathrm{~K}$, and $1473 \mathrm{~K}$, the experimental flame propagation distance is $0.84 \mathrm{~m}, 0.85 \mathrm{~m}, 0.86 \mathrm{~m}, 0.87 \mathrm{~m}, 0.88 \mathrm{~m}, 0.88 \mathrm{~m}$, $0.89 \mathrm{~m}, 0.90 \mathrm{~m}, 0.91 \mathrm{~m}, 0.93 \mathrm{~m}$, and $0.95 \mathrm{~m}$, and the numerical flame propagation distance is $0.87 \mathrm{~m}, 0.89 \mathrm{~m}, 0.90 \mathrm{~m}$, $0.91 \mathrm{~m}, 0.93 \mathrm{~m}, 0.94 \mathrm{~m}, 0.96 \mathrm{~m}, 0.98 \mathrm{~m}, 1.03 \mathrm{~m}, 1.05 \mathrm{~m}$, and $1.06 \mathrm{~m}$. The maximum error of the simulation result is $0.12 \mathrm{~m}$, and the simulation accuracy of this result is also acceptable.

In Figure 9, it is found that, as the ignition temperature increases, the flame propagation distance continues to increase, indicating that the ignition temperature has a great influence on the propagation process of coal dust cloud explosion flame. From the perspective of coal dust cloud explosion mechanism, the ignition temperature determines the rate at which the coal dust cloud releases combustible volatiles at the moment of ignition. Combustible volatiles are the main gas components involved in coal dust cloud explosion. Therefore, the increase of ignition temperature has an obvious effect on the flame propagation process of coal dust cloud explosion. 

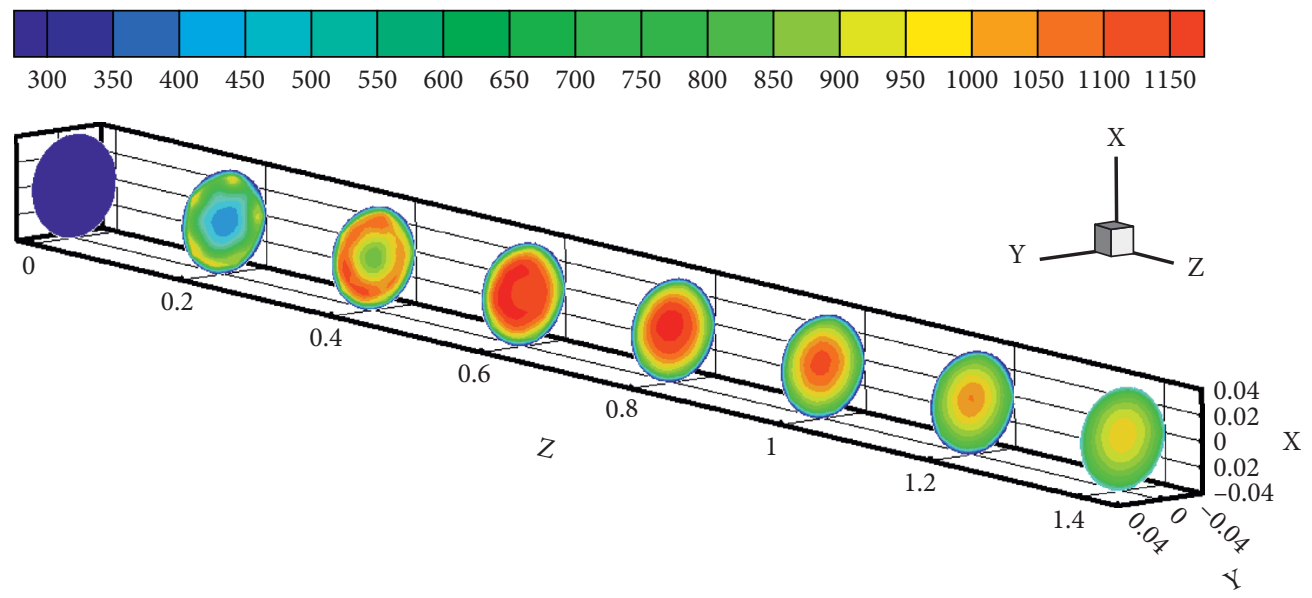

FigURE 7: Flame temperature at the time of $0.5 \mathrm{~s}$ after explosion.

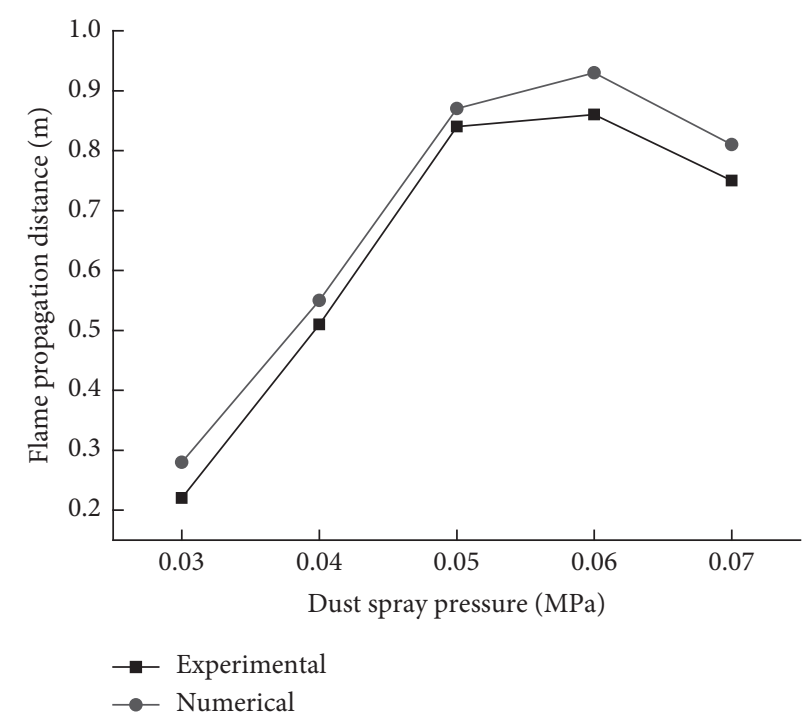

FIGURE 8: Experimental and numerical results of flame propagation distance under different dust spray pressure.



FiguRE 9: Experimental and numerical results of flame propagation distance under different ignition temperature. 


\section{Conclusions}

The aim of this study is to get better understanding of ignition energy characteristics and explosion propagation law of coal dust cloud. The following results were obtained.

Ignition delay time and dust spray pressure have obvious effects on the minimum ignition energy of coal dust cloud. When the ignition delay time is $1 \mathrm{~s}$, the minimum ignition energy is the smallest, indicating that the coal dust cloud reaches the most ignitable state. When the dust spray pressure is $0.3-0.4 \mathrm{MPa}$, coal dust cloud is the easiest to be ignited and the risk of explosion is greater.

By simulating flame propagation characteristics and contrasting the experimental and numerical results, it is found that the experimental flame propagation distance is $0.84 \mathrm{~m}$, the numerical flame propagation distance is $0.87 \mathrm{~m}$, the simulation error is $0.03 \mathrm{~m}$, which proves that the simulation accuracy is acceptable.

Dust spray pressure and ignition temperature have significant effects on the flame propagation distance of coal dust cloud explosion. When the spray pressure is $0.06 \mathrm{MPa}$, the flame propagation distance is the farthest, indicating that the turbulence of coal dust cloud is the largest at this condition. Increasing the ignition temperature will increase the release rate of combustible volatiles, thereby increasing the flame propagation distance.

\section{Data Availability}

The data are available within the article.

\section{Conflicts of Interest}

The authors declare that they have no conflicts of interest.

\section{Acknowledgments}

The authors appreciate the financial support from the Natural Science Foundation of China (Grant nos. 12102271 and 51774168), the Project of Liaoning Provincial Department of Science and Technology (Grant no. 2020-BS-175), and the Project of Liaoning Provincial Department of Education (Grant no. JYT19038).

\section{References}

[1] R. K. Eckhoff, "Current status and expected future trends in dust explosion research," Journal of Loss Prevention in the Process Industries, vol. 18, no. 4-6, pp. 225-237, 2005.

[2] G. Joseph, "Combustible dusts: a serious industrial hazard," Journal of Hazardous Materials, vol. 142, no. 3, pp. 589-591, 2007.

[3] Chemical Safety and Hazard Investigation Board, "Combustible dust hazard study," Investigation Report, Chemical Safety and Hazard Investigation Board, USA, 2006.

[4] W. Cao, W. Cao, Y. Peng, S. Qiu, N. Miao, and F. Pan, "Experimental study on the combustion sensitivity parameters and pre-combusted changes in functional groups of lignite coal dust," Powder Technology, vol. 283, pp. 512-518, 2015.
[5] H.-H. Xin, D.-M. Wang, G.-L. Dou, X.-Y. Qi, T. Xu, and G.-S. Qi, "The infrared characterization and mechanism of oxygen adsorption in coal," Spectroscopy Letters, vol. 47, no. 9, pp. 664-675, 2014.

[6] P. R. Amyotte and R. K. Eckhoff, "Dust explosion causation, prevention and mitigation: an overview," Journal of Chemical Health \& Safety, vol. 17, no. 1, pp. 15-28, 2010.

[7] X. Yan and J. Yu, "Dust explosion venting of small vessels at the elevated static activation overpressure," Powder Technology, vol. 261, pp. 250-256, 2014.

[8] G. Li, Y. Du, S. Qi, Y. Li, S. Wang, and B. Wang, "Explosions of gasoline-air mixtures in a closed pipe containing a T-shaped branch structure," Journal of Loss Prevention in the Process Industries, vol. 43, pp. 529-536, 2016.

[9] S. D. Emami, S. Z. Sulaiman, R. M. Kasmani, M. D. Hamid, and C. R. Che Hassan, "Effect of pipe configurations on flame propagation of hydrocarbons-air and hydrogen-air mixtures in a constant volume," Journal of Loss Prevention in the Process Industries, vol. 39, pp. 141-151, 2016.

[10] K. Wang, S. Jiang, X. Ma, Z. Wu, W. Zhang, and H. Shao, "Study of the destruction of ventilation systems in coal mines due to gas explosions," Powder Technology, vol. 286, pp. 401-411, 2015.

[11] C.-J. Zhu, Z.-S. Gao, X.-M. Lu, B.-Q. Lin, C. Guo, and Y.-M. Sun, "Experimental study on the effect of bifurcations on the flame speed of premixed methane/air explosions in ducts," Journal of Loss Prevention in the Process Industries, vol. 49, pp. 545-550, 2017.

[12] P. Zhang, Y. Du, Y. Zhou, S. Qi, S. Wu, and J. Xu, "Explosions of gasoline-air mixture in the tunnels containing branch configuration," Journal of Loss Prevention in the Process Industries, vol. 26, no. 6, pp. 1279-1284, 2013.

[13] W. Gao, T. Mogi, J. Sun, J. Yu, and R. Dobashi, "Effects of particle size distributions on flame propagation mechanism during octadecanol dust explosions," Powder Technology, vol. 249, pp. 168-174, 2013.

[14] W. Cao, W. Gao, Y. Peng, J. Liang, F. Pan, and S. Xu, "Experimental and numerical study on flame propagation behaviors in coal dust explosions," Powder Technology, vol. 266, pp. 456-462, 2014.

[15] Y. Yin, J. Sun, Y. Ding, S. Guo, and X. He, "Experimental study on flames propagating through zirconium particle clouds," Journal of Hazardous Materials, vol. 170, no. 1, pp. 340-344, 2009.

[16] W. Gao, T. Mogi, J. H. Sun, and R. Dobashi, "Effects of particle thermal characteristics on flame structures during dust explosions of three long-chain monobasic alcohols in an openspace chamber," Fuel, vol. 113, pp. 86-96, 2012.

[17] R. K. Eckhoff, "Understanding dust explosions. The role of powder science and technology," Journal of Loss Prevention in the Process Industries, vol. 22, no. 1, pp. 105-116, 2009.

[18] E. S. Oran, "Structure and flame speed of dilute and dense layered coal-dust explosions," Journal of Loss Prevention in the Process Industries, vol. 36, pp. 214-222, 2015.

[19] P. Kosinski and A. C. Hoffmann, "An investigation of the consequences of primary dust explosions in interconnected vessels," Journal of Hazardous Materials, vol. 137, no. 2, pp. 752-761, 2006.

[20] W. Cao, W. Gao, J. Liang, S. Xu, and F. Pan, "Flame-propagation behavior and a dynamic model for the thermal-radiation effects in coal-dust explosions," Journal of Loss Prevention in the Process Industries, vol. 29, pp. 65-71, 2014.

[21] W. Cao, Q. Qin, W. Cao et al., "Experimental and numerical studies on the explosion severities of coal dust/air mixtures in 
a 20-L spherical vessel," Powder Technology, vol. 310, pp. 17-23, 2017.

[22] V. Giovangigli and M. D. Smooke, "Extinction of strained premixed laminar flames with complex chemistry," Combustion Science and Technology, vol. 53, no. 1, pp. 23-49, 1987.

[23] C. Y. Zhang and X. F. Sun, "Numerical simulation on vortex shedding and combustion oscillation in aero-engine afterburner," Journal of Aerospace Power, vol. 25, pp. 270-277, 2010.

[24] T. H. Shah, W. W. Liou, and A. Shabbir, "A new $k-\varepsilon$ Eddy viscosity model for high Reynolds number turbulent flows model development and validation," Computers \& Fluids, vol. 24, pp. 227-238, 1995.

[25] B. E. Lauder and D. B. Spalding, "The numerical computation of turbulent flows," Computer Methods in Applied Mechanics and Engineering, vol. 3, pp. 269-289, 1974. 